\title{
Educação entre pares: protagonismo juvenil na abordagem preventiva de álcool e outras drogas
}

\author{
Peer education: youth protagonism in a preventive approach \\ to alcohol and other drugs
}

\author{
Maria Regina Araújo de Vasconcelos Padrão (https://orcid.org/0000-0003-2411-9404) ${ }^{1}$ \\ Ana Júlia Tomasini (https://orcid.org/0000-0002-7900-8878) ${ }^{2}$ \\ Maria Laura Alves de Moura Romero (https://orcid.org/0000-0002-0365-0258) ${ }^{1}$ \\ Douglas Silva (https://orcid.org/0000-0001-8269-172X) ${ }^{1}$ \\ Aline Guio Cavaca (https://orcid.org/0000-0001-7314-584X) ${ }^{1}$ \\ Luciana Sepúlveda Köptcke (https://orcid.org/0000-0001-7079-6575) ${ }^{1}$
}

${ }^{1}$ Diretoria Regional de Brasília, Fundação Oswaldo Cruz. Campus Universitário Darcy Ribeiro, Asa Norte. 70750540 Brasília DF Brasil. regina.padrao@fiocruz.br ${ }^{2}$ Programa de PósGraduação em Bioética, Universidade de Brasília. Brasília DF Brasil.

\begin{abstract}
This article describes the experience of the course in Health and Safety at School, which prepared young people to spread knowledge on prevention of alcohol and other drugs, using the peer education methodology. The participants were sixty 15 to 19 year-old upper secondary school students from 8 public schools in the Federal District. The activity was structured into 8 modules, with each module consisting of a meeting to discuss content, followed by field work at the schools, where students trained their colleagues and passed on information to them; and, lastly, a further meeting for the students to give feedback on their experience in the field. All activities were recorded in field diaries, photographs, and reports, providing input to this experience report. Final$l y$, a student forum was held at which the young people presented projects to be carried out at the schools. The peer education experience enabled the young people to take the lead in their school community and territory, and acknowledged the value of sharing among people with similar experiences. It thus favoured the development of critical, artistically potent strategies for preventive action directed to adolescents in situations of social vulnerability and fostered health promotion in the school.
\end{abstract}

Key words Health education, Adolescent, Illicit drugs, Alcoholism
Resumo $O$ artigo objetiva descrever a experiência do curso Saúde e Segurança na Escola, que formou jovens para a multiplicação de saberes na prevenção de álcool e outras drogas, por meio da metodologia da educação entre pares. O curso teve a participação de 60 jovens do Ensino Médio, entre 15 e 19 anos, de oito escolas da rede pública do Distrito Federal. A atividade foi estruturada em oito módulos, sendo um encontro de debate de conteúdo; um segundo momento de atuação em campo nas escolas, em que os educandos fizeram a formação/multiplicação com seus colegas; e, por fim, um novo encontro para a devolutiva dos educandos a respeito da experiência no campo. Todas as atividades foram registradas em diários de campo, fotografias e relatórios, subsidiando o presente relato de experiência. Ao final, foi realizado um fórum de estudantes, no qual os jovens apresentaram os projetos a serem desenvolvidos nas escolas. A experiência de educação entre pares permitiu o protagonismo juvenil em sua comunidade escolar e em seu território, valorizando a troca entre pessoas com experiências semelhantes. Assim, viabilizou a elaboração de estratégias críticas e artisticamente potentes para ações de caráter preventivo direcionadas a adolescentes em situação de vulnerabilidade social, fomentando a promoção da saúde no ambiente escolar.

Palavras-chave Educação em saúde, Adolescentes, Drogas ilícitas, Alcoolismo 


\section{Introdução}

O consumo de substâncias psicoativas remonta à antiguidade, associado, majoritariamente, a rituais, eventos e finalidades preestabelecidas pelas regras culturais dos diferentes grupos humanos ${ }^{1,2}$. Os problemas de saúde e violência resultantes do consumo dessas substâncias recrudesce à medida em que a droga se torna uma mercadoria, lícita ou ilícita, responsável tanto por excitar e propiciar prazer, quanto por anestesiar ou aliviar o sofrimento, que produz grande lucro, coadunando os modos de produção capitalistas ${ }^{3}$.

Em 2019, o Relatório Mundial sobre drogas evidenciou que 35 milhões de pessoas, em todo o mundo, sofrem de transtornos por uso de substâncias psicoativas e precisam de tratamento ${ }^{4}$. No Brasil, o uso de álcool e outras substâncias estão entre os principais fatores de risco para a morte e incapacidade ${ }^{5}$.

Os adolescentes são especialmente vulneráveis ao uso de álcool e outras drogas, pois, nessa fase da vida, buscam vivenciar e explorar com intensidade as descobertas sobre si e sobre a sociedade, bem como almejam o pertencimento a grupos e identificações entre pares ${ }^{6}$. Parece haver uma dificuldade vivenciada por professores e pais em dialogar honestamente com esses jovens sobre a temática, com as intervenções prioritariamente baseadas no medo e na completa abstinência, não apresentando resultados eficazes de prevenção ao uso precoce e nem ao abuso dessas substâncias?

É importante destacar que as classes sociais, assim como gênero e raça, diferenciam os jovens na diversidade de suas situações existenciais ${ }^{8} \mathrm{com}$ desdobramentos na expressão do consumo, nos prejuízos desse uso e também na maneira como as famílias dispõem de recursos para lidar com o problema ${ }^{9}$. Vale ressaltar que os jovens contabilizam $54,8 \%$ da população carcerária brasileira, sendo que muitas dessas prisões são relacionadas ao consumo e ao tráfico de drogas ${ }^{10}$. Nesse sentido, as condições socioeconômicas e raciais são fatores determinantes quanto ao perfil dos jovens encarcerados, marcados majoritariamente por serem homens negros, pobres e de baixa escolaridade, o que ilustra a concretude da desigualdade social e racial no Brasil e o processo de criminalização da pobreza ${ }^{11,12 .}$

Ao falarmos sobre a juventude, a educação costuma aparecer como um componente central para articular a prevenção ao uso de álcool e outras drogas, bem como a promoção da saúde, e sua relação com os indivíduos e a socieda- $\mathrm{de}^{13}$. Isso porque a escola constitui um fator de proteção para adolescentes e jovens com relação ao uso abusivo de álcool e outras drogas, já que apresenta um contexto em que é possível fortalecer o vínculo entre os jovens e destes jovens com adultos de confiança e, ainda, promover o desenvolvimento de habilidades sociais, de autoestima e autoconfiança, considerados fatores individuais de proteção ${ }^{14}$. Ademais, a escola oferece um espaço privilegiado para a prevenção, por garantir a presença dos jovens em seu recinto, de forma continuada, ao contrário dos serviços de saúde pouco procurados por este grupo ${ }^{15}$. Assim, as possibilidades educacionais se multiplicaram, a partir do século XX, tanto nos cenários de educação formal nas escolas, quanto nos espaços de existências e pluralidades de educação não-formal e informal ${ }^{16}$.

Considera-se o potencial do espaço escolar para a promoção de socialização, ampliação de diálogos/debates e vivências dos jovens. Entretanto, para explorar a fertilidade de tal espaço, é preciso compreender a importância da escola assumir uma proposta inspirada na Pedagogia Histórico-Crítica. A escola, nesta perspectiva, deve reconhecer a realidade circundante do educando, valorizar a sua potencialidade e realizar uma educação crítica e transformadora, empoderando o jovem para atuar no coletivo e construir alternativas para seu projeto de vida e condições de pertencimento social ${ }^{17}$.

A abordagem sobre álcool e outras drogas, durante décadas, não foi realizada nas escolas, com base na convicção de que somente os especialistas na área poderiam recomendar estratégias de prevenção para tal contexto. O campo da Educação, no Brasil, apropria-se da temática em um registro pioneiro, em $1970^{18}$. Paulatinamente, percebe-se uma mudança gradual no entendimento de que a prevenção não é facultada apenas aos especialistas, sendo todos os cidadãos aptos a realizarem ações preventivas em algum campo ${ }^{19}$.

No campo das ações de educação para a promoção da saúde e a prevenção de agravos, observa-se no Brasil o aumento do uso da estratégia da educação entre pares, desde a década de 1990, na perspectiva da redução de danos e, a partir dos anos 2000, no ambiente escolar ${ }^{15}$. Estudos em outros países identificam tendência similar..$^{20,21,22}$

A educação entre pares sinaliza uma estratégia profícua de abordagem da temática dentro do grupo, contribuindo para a identificação dos jovens com o tema que, abordado por outros jovens, diminui as barreiras culturais ${ }^{23}$. Esta estratégia possibilita formar indivíduos que se iden- 
tifiquem com quem está mediando a atividade. No caso da juventude, formar jovens estudantes que possam debater diversas temáticas de uma forma mais naturalizada. A educação popular e a educação entre pares mostram como premissa a intenção de transformar a realidade em uma aproximação para reconhecimento e também valorização de experiências e saberes. É garantindo espaços de fala e interação de quem vive no contexto sobre a temática a ser trabalhada e que por ele é afetado que se entende a realidade. Detém, assim, potencial de ser um agente de transformação dessa realidade ${ }^{24}$.

A prevenção do uso de álcool e outras drogas por meio de uma metodologia entre pares permite a maior facilidade comunicacional, a identificação entre os indivíduos envolvidos e o maior envolvimento e empoderamento dos participantes, além da aproximação a grupos normalmente “invisíveis" ou de difícil acesso para profissionais da saúde, da assistência social ou da educação ${ }^{20}$. Observa-se, também, que o conhecimento compartilhado por educadores pares costuma ser mais prático, mais próximo da realidade (menos teórico), além de conseguirem estabelecer uma relação mais horizontal, afetiva, informal entre educandos e educadores ${ }^{20}$.

A partir do paradigma compreensivo e contextualizado da prevenção ${ }^{15}$, a utilização da estratégia da educação entre pares pode ajudar em diversas circunstâncias. Em escolas que já desenvolvem ações de prevenção, naquelas que enfrentam problemas de consumo e/ou tráfico dentro e ao redor da própria escola, ou ainda, junto a escolas que trabalham com adolescentes que já se encontram em situação de risco e vulnerabilidade. Nesta metodologia, os jovens atuam como facilitadores e multiplicadores de ações junto a seus pares, podendo realizar atividades como oficinas, atividades artísticas, rodas de conversas, dentre outras.

A partir de uma abordagem com foco no fortalecimento de fatores de proteção para a prevenção do uso de álcool e outras drogas, no final de 2018, a Fundação Oswaldo Cruz em Brasília (Fiocruz Brasília), em parceria com a Universidade de Brasília (UnB) e a Secretaria Nacional de Políticas sobre Drogas, do Ministério da Justiça (SENAD/MJ) iniciou o projeto Prevenção ao Uso de Álcool e outras Drogas no território educacional.

A iniciativa articula ações de natureza educacional para a promoção da saúde e a prevenção ao uso abusivo de drogas no território escolar, abrangendo educandos, educadores, servidores da educação, saúde e assistência social, familia- res, comunidades e setores ligados aos Direitos Humanos ${ }^{25}$.

Nesse contexto, o objetivo desse artigo é descrever a experiência do curso Saúde e Segurança na Escola na modalidade voltada para a formação de 60 jovens estudantes para a multiplicação de conhecimentos e saberes na prevenção de álcool e outras drogas, por meio da metodologia da educação entre pares, no Distrito Federal.

\section{Metodologia}

\section{Contexto institucional e espaço-temporal}

Trata de um relato e análise crítica da experiência de educação entre pares na abordagem preventiva sobre álcool e outras drogas, no contexto do projeto Prevenção ao Uso de Álcool e outras Drogas no território educacional.

O curso Saúde e Segurança na Escola, na modalidade presencial entre pares, do qual trata o presente artigo, foi realizado pelo Programa de Educação, Cultura e Saúde, da Fiocruz Brasília, no período de 28 de agosto a 29 de novembro de 2019.

\section{Cenário e atores do estudo}

O curso Saúde e Segurança na Escola, modalidade presencial entre pares, foi ofertado para estudantes do Ensino Médio. A partir da escuta aos parceiros institucionais e de prioridades epidemiológicas, foram selecionadas oito escolas da rede pública do Distrito Federal, localizadas em cinco regiões administrativas: Plano Piloto, Sobradinho I, Sobradinho II, Paranoá e Itapoã.

O curso contou com a participação de 60 jovens do Ensino Médio, na faixa etária entre 15 e 19 anos. A seleção ficou a cargo da Fiocruz Brasília, por meio de chamada pública simplificada contendo os seguintes critérios de seleção: ser liderança juvenil, ter habilidade de transitar pelos diversos ambientes da escola, habilidade de articulação com os diferentes atores (gestão escolar, corpo docente, discente, pais e comunidade), interesse pelo tema da prevenção ao uso de álcool e outras drogas, disponibilidade de tempo e pertencer à família beneficiária do Programa Bolsa Família. Foram selecionados 72 educandos e, ao final, a atividade foi concluída por 60 estudantes. A principal justificativa de evasão desses 12 educandos foi a inserção no mercado de trabalho, seja através de estágios ou empregos formais. 


\section{Registro das atividades e análise dos dados}

O curso na modalidade entre pares foi estruturado no seguinte formato: para cada um dos oito módulos, houve um encontro de debate de conteúdo no espaço da Fiocruz Brasília; um segundo momento de atuação em campo nas escolas, onde os educandos fariam a formação com seus colegas; e, por fim, um novo encontro na Fiocruz Brasília para a devolutiva dos educandos a respeito da experiência no campo, relatando as dinâmicas utilizadas, os pontos positivos e as dificuldades enfrentadas nos espaços escolares. Ao todo foram 76 horas de curso. Todas as atividades foram registradas em diários de campo, fotografias e relatórios de pesquisa. Esse material empírico foi analisado e discutido criticamente pelos pesquisadores, subsidiando o presente relato de experiência.

\section{Resultados e discussão}

\section{O Planejamento da atividade}

O projeto propôs um processo de ensino -aprendizagem no qual o jovem educando atuasse ativamente em todo o processo formativo, seja na condução do processo, seja no auxílio ao direcionamento dos temas e formato da ação educativa. Dessa forma, a equipe responsável pela ação elaborou o Projeto Pedagógico como fio condutor e, durante o caminhar da formação e a partir do feedback dos educandos, estruturouse o processo formativo, em consonância com o projeto inicial.

Promover a saúde e a prevenção ao uso de álcool e outras drogas no território educativo, sob a ótica intersetorial, remete à Política de Educação Integral no Brasil ${ }^{26}$ que considera o sujeito e seu contexto, valorizando a diversidade sociocultural e a participação dos jovens na condução do processo educativo. Nessa perspectiva, crianças, adolescentes e jovens devem exercer um protagonismo positivo no âmbito do território da escola, podendo partir de metodologias emancipatórias - como a educação entre pares -, propostas fundadas no protagonismo juvenil.

A centralidade do território nessa experiência mostra como se constrói a relação da juventude e identidade, em seu cotidiano, com seus grupos, escolas e moradias. Como parte do projeto, no momento de trabalho de campo, as ações relativas à prevenção de álcool e outras drogas ocorreram nas escolas dos estudantes.

\section{A dinâmica do curso Saúde e Segurança nas Escolas}

A partir do planejamento inicial e do diagnóstico territorial, o projeto pedagógico do curso foi elaborado em oito módulos, e que para cada módulo houve um encontro de debate de conteúdo na Fiocruz Brasília; um segundo momento de atuação em campo nas escolas, onde os educandos fizeram a formação/multiplicação com seus colegas; e, por fim, um novo encontro na Fiocruz para a devolutiva dos educandos a respeito da experiência no campo. Ao final, foram realizados três encontros para organização do Fórum dos Estudantes e Avaliação do processo como um todo.

Os conteúdos abordados no curso foram sintetizados no Quadro 1.

A apresentação dos conteúdos foi feita pelos tutores do curso e por especialistas convidados, por meio de aulas expositivas-dialogadas e muitas dinâmicas lúdicas, as quais permitiram o estreitamento de laços e vínculos de afeto entre todo o grupo, tanto entre os estudantes, como entre estudantes e a equipe de educadores.

\section{O primeiro encontro: apresentação e pacto de convivência}

Conduziu-se no primeiro encontro a apresentação do grupo de estudantes e educadores,

Quadro 1. Conteúdos apresentados no curso Saúde e Segurança na Escola, modalidade presencial entre pares, Brasília, 2019.

\begin{tabular}{|l|l|}
\hline $\begin{array}{c}\text { Primeiro } \\
\text { encontro }\end{array}$ & Apresentação da atividade e equipe \\
\hline Módulo 1 & Educação entre pares \\
\hline Módulo 2 & Diagnóstico territorial \\
\hline Módulo 3 & $\begin{array}{l}\text { Usos históricos e sociais das } \\
\text { substâncias psicoativas }\end{array}$ \\
\hline Módulo 4 & Motivos que levam ao uso de drogas \\
\hline Módulo 5 & Tipos de drogas e seus efeitos \\
\hline Módulo 6 & Tratamentos/ Redução de danos \\
\hline Módulo 7 & Fato ou boato \\
\hline Módulo 8 & $\begin{array}{l}\text { A Escola e a prevenção ao uso de } \\
\text { drogas }\end{array}$ \\
\hline $\begin{array}{l}\text { Preparação } \\
\text { para o fórum }\end{array}$ & \\
\hline $\begin{array}{l}\text { Fórum dos } \\
\text { Estudantes }\end{array}$ & \\
\hline
\end{tabular}

Fonte: Elaborado pelos autores. 
através de uma dinâmica de abertura e uma explicação de todo o processo do curso, a pactuação do cronograma, bolsas, transporte e projeto de intervenção. Foi firmado um pacto de convivência construído coletivamente, no qual o grupo estabeleceu o conjunto de regras importantes de respeito às quais todos deveriam se atentar durante todo o curso, dentre elas: saber discordar com educação, respeitar a sua vez de falar, não fazer falas desrespeitosas, entre outras.

\section{A educação entre pares nas escolas: conteúdos, devolutivas, saúde mental e mudanças de planos}

No processo de trabalho de campo junto às escolas, os educandos discutiam com seus pares os conteúdos debatidos nos módulos teóricos realizados na Fiocruz, acompanhados da equipe de educadores. Nesses espaços, criou-se um círculo de confiança entre todos os atores envolvidos. Como consequência, os coordenadores das escolas do projeto solicitaram que os pesquisadores/ educadores incluíssem no encontro de devolutiva dos trabalhos de campo um momento de reflexão, que chamamos de "Rodas de Saúde Mental" - descritas mais adiante, e que relata uma grande preocupação com o crescente número de casos de depressão, automutilação e tentativas de suicídio entre os jovens das escolas.

Dessa maneira, a "adaptação curricular" da atividade deu-se mediante a percepção de educandos, docentes e diretores das escolas sobre a necessidade de diálogo franco e horizontal a respeito tanto da temática de álcool e outras drogas, como dos sofrimentos juvenis contemporâneos, atravessados pelas condições de saúde mental, depressão e suicídio. Assim, em um primeiro momento de avaliação da atividade, um educando relatou que o curso havia desconstruído o paradigma de educação que eu tinha, porque vocês escutam o que a gente diz. Tem sido uma experiência positiva. E vocês sabiam o meu nome desde o primeiro dia de aula, e eu me senti importante por isso.

Nesse sentido, vale ressaltar que as práticas pedagógicas do curso se inspiram na educação crítica proposta por Paulo Freire ${ }^{27}$ e Bell Hooks ${ }^{28}$. Portanto, não coaduna com uma educação bancária, que percebe o educando como consumidor passivo de informações. Ao contrário, defende educação como prática de liberdade a partir da conscientização. Consciência acompanhada de um engajamento crítico, práxis. Neste contexto, professores e educandos existem como partici- pantes ativos e não consumidores passivos, a fim de agirem e refletirem sobre o mundo para modificá-lo, comprometidos com práticas pedagógicas progressistas.

Hooks $^{28}$ defende que a sala de aula deve ser um lugar de entusiasmo, nunca de tédio, não podendo ser usada para perpetuar formas de controle baseadas na dominação, um lugar de castigo e reclusão (p. 17), mas sim criar um espaço de promessas e possibilidades de uma outra realidade melhor, de trocas, respeito, aprendizados e capacitação a ocupar espaços de falas importantes para promover as rupturas sociais necessárias, bem como estimular o pensamento crítico sobre as informações que são recebidas no cotidiano.

No contexto do campo nas escolas, é relevante registrar a singularidade das experiências em cada espaço, conforme a disponibilidade e organização da escola. Em geral, todas as turmas participaram ativamente, com exceção de uma turma que rejeitou enfaticamente a atividade. Algumas escolas finalizaram as atividades propondo peças de teatro, rodas de conversa e uma avaliação espontânea dos educandos, na qual um jovem considerou que rolou uma conexão, uma liberdade para conversar, foi muito bonito, muito legal, e um colega complementou: Teve uma resistência no início, mas depois faltou cadeira. Perguntamos sobre o uso de drogas, mas as pessoas acabaram falando sobre depressão também.

Nessa vivência nos territórios, estudantes trouxeram contribuições críticas muito enfáticas sobre guerra às drogas e extermínio da juventude negra, sobre o racismo, e a dificuldade de dialogar na família e na escola sobre esses temas considerados tabus e, como consequência, desabafaram sobre a ansiedade, insegurança e tristeza que sentem por não terem com quem conversar.

Nesse sentido, a metodologia da Educação entre pares se apresenta como uma importante ferramenta, servindo como meio de reforçar relações entre os membros de grupos semelhantes ${ }^{29}$. Os/as jovens educadores/as de pares são vistos, muitas vezes, como amigos ou irmãos mais velhos a quem se pede conselhos e por isso podem influenciar positivamente atitudes e comportamentos $^{30}$. Assim, os jovens educadores criaram um espaço livre e seguro para debater temáticas difíceis de serem abordadas usualmente nas escolas. Buscaram, também, compreender o significado do uso de álcool e outras drogas, compartilharam conhecimentos e experiências sobre o tema, tornando-se mais fácil a comunicação e a construção de sentido sobre as informações de prevenção. Os processos educativos estabelecidos 
na formação dos jovens para atuarem como educadores de seus pares resultam em intervenções contextualizadas que buscam trabalhar com a escola e os pares, além da família, fortalecendo os fatores protetores individuais, como a autoestima e autoconfiança, e acolhendo de forma afetiva os participantes. A escola pode tornar-se um espaço acolhedor e seguro capaz de enriquecer os fatores de proteção tanto individuais como extrafamiliares e a educação entre pares torna-se uma ferramenta importante para estas intervenções.

\section{A devolutiva do campo: rodas de saúde mental e empatia}

Nos encontros de devolutiva, após os estudantes relatarem como foi o campo nas escolas, realizou-se as rodas de conversa batizadas de "Rodas de Saúde Mental", nas quais foram abordados temas relativos a mitos e verdades sobre o uso de drogas e saúde mental, informações científicas sobre a prevenção ao suicídio, sonhos e projetos.

O presente trabalho concebe a saúde a partir de abordagem biopsicossocial, na qual se preconiza questões importantes para a saúde mental como o bem viver, o ambiente, as relações sociais $^{31}$. Essa compreensão permite uma análise mais holística do que se entende por saúde e saúde mental; e também mostra a importância da sociedade além dos indivíduos em uma construção que objetive maior saúde, dado a importância de se debater questões sociais estruturais que afetam diretamente na saúde, como racismo, machismo e os determinantes sociais da saúde ${ }^{32}$.

A Organização Mundial de Saúde (OMS), para finalidades estatísticas e políticas, define alguns limites cronológicos como as idades de 10 a 19 anos a adolescência, e entre 15 a 24 anos a juventude. Essa definição é dinâmica, pois a experiência de ser jovem é fluida e pode mudar de acordo com as pluralidades de existência. Para Bourdieu $^{33}$, a juventude decorre da relação de poder entre as gerações, visto que as diferenças materiais e afetivas dos jovens mostram que são lugares sociais e culturais diferentes, com possibilidades diversificadas.

Desta forma, é importante ressaltar que os estudantes do curso partem de territórios periféricos e estudam em escolas públicas do Distrito Federal. Ao falarmos da saúde mental da juventude, especialmente nesse grupo de jovens estudantes, precisamos também falar dos Determinantes Sociais da Saúde (DSS), em que estão inclusos os fatores sociais, econômicos, culturais e étnicos, que incidem nas condições de vida e nos estilos de vida dos jovens estudantes ${ }^{32}$. Neste sentido, enfatizamos a importância da construção da escola como espaço de liberdade e confiança, algumas vezes como contraponto a situações abusivas experimentadas pelos jovens na comunidade e nas famílias.

Nas discussões voltadas para o consumo de substâncias, os educandos demonstram vasto conhecimento para a forma na qual as mídias e autoridades diferenciam no tratamento aos jovens com maior poder aquisitivo e adolescentes pobres, destacando também a desigualdade racial, trazendo-nos à memória um trecho da música "O homem na estrada", do grupo de Rap Racionais Mc's: Os ricos fazem campanha contra as drogas, e falam sobre o poder destrutivo delas. Por outro lado promovem e ganham muito dinheiro com o álcool que é vendido na favela ${ }^{34}$.

$\mathrm{Na}$ primeira roda de conversa sobre saúde mental, abordamos a temática do suicídio. Tratase da segunda causa de morte entre jovens de 15 a 29 anos no mundo, atrás apenas de acidentes de trânsito, sendo que $79 \%$ dos casos se concentram em países de baixa e média renda ${ }^{35}$.

Nos depoimentos emergiram questões como: falta de amor próprio, sofrimento, histórico de depressão, remédios, felicidade momentânea, vazio impreenchível, medo, falta de afeto, ser encarado como doido, falar e não ser ouvido. Depois dessas questões que foram pontuadas de forma coletiva, alguns estudantes fizeram relatos da própria vivência, seja com eles mesmos ou com amigos próximos ou primos.

Nesses relatos da vivência, questões como abuso sexual, depressão, masculinidade tóxica, pressão familiar e social, dificuldade de ser LGBTI, racismo, falta de empatia, gordofobia, falta de condições materiais e falta de oportunidades são importantes marcadores, pois lançadas muito cedo na brutal experiência social, estas crianças são obrigadas a serem jovens e mesmo adultos muito cedo, convivendo precocemente com coisas terriveis e mesmo quase impossíveis, para as suas idades


tender que a saúde mental precisa ser debatida na sua relação com as estruturas e as desigualdades sociais, ao passo que o uso das drogas se diferencia tanto no consumo, como na prevenção dado a pluralidade de vivências. As disponibilidades de estratégias como, por exemplo, a escuta de sofrimentos, são importantes ferramentas de prevenção ao uso prejudicial das drogas à medida que permite elaboração e ressignificação da experiência social. 
Após essa difícil catarse coletiva, a roda foi encerrada com um momento lúdico e amoroso com a poeta Memei Bastos, que propôs como atividade o Slam - uma competição de poesia que é falada na hora - na qual se tem um espaço para livre expressão poética. Os estudantes participaram efetivamente com belas poesias.

As demais rodas de saúde mental propiciaram debates transversais sobre a questão do uso de álcool e outras drogas, relacionando-o à relevância da família, aos sonhos e projetos de vida dos jovens, à masculinidade tóxica, às questões sobre violências e sobre sexualidade.

Sabe-se que a família tem um importante espaço de atuação na vida dos jovens e, muitas vezes, é a produtora e reprodutora de violência, ao introduzir novos entendimentos sobre abusos, assédios e violência ${ }^{37}$. No discurso dos estudantes se observa as violências que ainda passam como pontos reguladores tanto na família como nas escolas, nas amizades, na vivência.

Em uma das avaliações das atividades, os estudantes trouxeram relatos como: Nunca imaginei muitos sonhos dos colegas, foi legal que nos conhecemos mais. Percebemos sonhos em comum. Temos sonhos próximos, de ajudar os outros e as outras pessoas. São sonhos ligados - Juntar sonhos dá força. Nessa hora uma estudante lembra do roqueiro baiano Raul Seixas ${ }^{38}$ no prelúdio Sonho que se sonha só é só um sonho que se sonha só, sonho que se sonha junto é realidade.

Finalmente, no último encontro, foi organizado um Fórum dos Estudantes que contou com a participação de autoridades financiadoras do projeto, coordenadores, professores, além dos jovens e alguns familiares dos participantes. Todos os estudantes apresentaram os projetos a serem desenvolvidos nas escolas, relacionados à temática de prevenção do álcool e outras drogas. Finalmente, houve um momento artístico, no qual vários jovens cantaram, declamaram poesias e contaram como foi vivenciar o curso. Houve uma formatura simbólica, na qual cada participante recebeu um certificado de conclusão do curso.

É certo que existem inúmeras metodologias que propõem a participação ativa dos jovens no espaço escolar e em espaços informais e não-formais. Contudo, em sua maioria, são demarcadas pelo debate entre os educadores e seus educandos. A educação entre pares, no entanto, é um processo potente de ensino-aprendizagem, em que os próprios atores envolvidos são responsáveis por desenvolver ações educativas para o grupo do qual faz parte. As pessoas de um mesmo grupo (no caso, os jovens) são os facilitadores de ações e atividades com e para seus pares $^{39}$. Assim, o educador de pares aprende a utilizar vários conhecimentos na organização de uma ação, envolvendo-se com a realidade a sua volta, compartilhando as ideias e estratégias do aprendizado adquirido, com uma linguagem de "igual para igual", sempre fundamentando-se no conhecimento da realidade dos colegas e da comunidade dos participantes, com a valorização e busca de atividades junto à cultura e parcerias locais ${ }^{40}$.

\section{Considerações finais}

A experiência de educação entre pares para educação em saúde sobre álcool e outras drogas permitiu o protagonismo juvenil em sua comunidade escolar e seu território como um todo, fomentando o compartilhamento de ideias, dúvidas e opiniões entre os próprios adolescentes, e valorizando a troca entre pessoas com experiências semelhantes. Importante destacar que a colaboração na aprendizagem entre pares se realiza em um espaço fluido de acolhimento e livre de rejeição, que nos induz a repensar as estratégias traçadas previamente, dada a diversidade, riqueza e complexidade de conviver em uma sociedade multicultural. Relatamos aqui, principalmente a experiência dos 60 jovens formados para atuarem como educadores de pares no território educativo.

Dentre os fatores que garantiram a viabilidade da experiência, destaca-se a oferta de transporte, alimentação e uma bolsa de estudos aos educandos participantes, que forneceu condições materiais indispensáveis para manterem os estudantes vinculados ao curso até o final. Este ponto é importante, visto que grande parte das experiências similares relatadas utilizam o voluntariado com ajuda de custo ou a contratação de um educador de pares com experiência. A escolha da equipe do projeto residiu na seleção de jovens das escolas onde a ação ocorreria, e formá-los. O investimento em uma longa formação, assim como a inclusão de conteúdos práticos voltados para a aquisição ou fortalecimento de habilidades sociais, como o respeito, a capacidade de escuta e o acolhimento da diversidade foram fundamentais para alcançar os resultados. Outra iniciativa importante foi a criação de um grupo de whatsa$p p$ do curso, no qual os educandos e educadores podiam compartilhar informações, dúvidas e angústias pessoais, o que permite um espaço protegido de afeto e compartilhamento, bem como de uma rede de apoio. 
Existiram alguns poucos momentos de conflito entre os jovens, contornados pela equipe com muito diálogo e repactuação de algumas regras, que viabilizaram a convivência entre os colegas. Problemas como este foram igualmente relatados em outras ocasiões ${ }^{20}$ pois envolvem a dificuldade de trabalhar em equipe, geralmente formada pelos educadores pares e técnicos ou especialistas no assunto. Algumas vezes, os jovens reproduzem o papel de autoridade em seu gesto e fala, repetindo assimetrias de poder presentes na educação formal e sofrendo com a indefinição de papéis ${ }^{15,41}$. O atraso no pagamento de algumas bolsas também foi apontado como aspecto negativo da experiência por alguns educandos.

Desta experiência destacam-se algumas reflexões: a primeira é a importância de colocar em prática uma pedagogia do afeto e do respeito garantindo maior horizontalidade nas relações, sem que os educadores se coloquem como uma autoridade absoluta perante os estudantes - na perspectiva de empoderamento do jovem como fator de proteção diante do uso prejudicial de álcool e drogas. A segunda, e não menos importante, é que a sociedade perde ao não ouvir seus jovens, que têm muito a contribuir com suas vivências repletas de energia, opinião, criatividade e afeto. A maior participação juvenil nas políticas de saúde e na sociedade em geral é um fator de promoção da saúde para todos os envolvidos.

Ao lançar mão de uma proposta de confluência da educação emancipatória, com o afeto, valorização das individualidades e criação de um ambiente de entusiasmo na relação com os jovens, almejamos que estes, ao se formarem dinamizadores, construam análises críticas sobre os conteúdos apresentados (e outros decorrentes), sobre a realidade social que permeia tais debates; e que todo o processo formativo se dê de modo a não reproduzir as estruturas enrijecidas das relações de poder social, como por exemplo a relação educador-educando, prevalecendo um esforço por autonomia real ${ }^{42}$.

\section{Colaboradores}

MRAV Padrão trabalhou na concepção, delineamento, análise dos dados e redação do artigo. AJ Tomasini, MLAM Romero e D Silva trabalharam na redação do artigo. AG Cavaca trabalhou na análise e interpretação dos dados e redação do artigo. LS Köptcke trabalhou na concepção, delineamento do estudo, revisão crítica do artigo e aprovação da versão a ser publicada. 


\section{Referências}

1. Guerra-Doce E. Psychoactive substances in Prehistoric Times: Examining the Archaeological Eidence. Time and Mind [serial on the Internet.]2015 Jan [cited 2020 Jan 18]; 8(1):[about 21 p.]. Available from: https://www.tandfonline.com/doi/full/10.1080/17516 96X.2014.993244.

2. Lopes MA. Drogas: 5 mil anos de viagem. Super Interessante 2006 Jan 30. [acessado 2020 jan 1]. Disponível em: https://super.abril.com.br/ciencia/drogas-5-mil-anos -de-viagem/

3. Paixão IR, Soares C B, Oliveira L C, Cordeiro L, Trapé C A, Campos C M S. Drogas e sociedade: material de apoio a atividades educativas na perspectiva emancipatória. Trabalho, Educação e Saúde [periódico na internet]. 2018 Abr [acessado 2020 Jan 20]; 16(2):[cerca de 20 p.]. Disponível em: http://www.scielo.br/ scielo.php?script $=$ sci_arttext\&pid $=$ S198177462018 000200621\&lng=en\&nrm=

4. World Health Organization (WHO). World Drug Report 2019, UNODC (United Nations Office on Drugs and Crime). [cited 2020 Jan 23]. Available from: https://www.unodc.org/lpo-brazil/pt/drogas/relatorio -mundial-sobre-drogas.html

5. Bastos FIPM, Vasconcellos MTL, Boni RB, Reis NB, Coutinho CFS. III Levantamento Nacional sobre o uso de drogas pela população brasileira. Rio de Janeiro: Fiocruz; 2017.

6. Vasters GP, Pillon SC. O uso de drogas por adolescentes e suas percepções sobre adesão e abandono de tratamento especializado. Rev Latino-Am Enferm [periódico de Internet]. 2011 abr [acessado 2020 fev 2]; 19(2):[cerca de 7 p.]. Disponível em: http:// www.scielo.br/scielo.php?script $=$ sci_arttext\&pi$\mathrm{d}=$ S010411692011000200013\&lng=en.

7. Rosenbaum M. Proteção em Primeiro Lugar. Uma abordagem honesta sobre a questão do uso de drogas por adolescentes. Instituto Igarapé. 2018 jun. [acessado $2020 \mathrm{fev} 3$ ] [cerca de 60 p.]. Disponível em: https://igarape.org.br/wp-content/uploads/2018/06/ Protec\%CC\%A7a\%CC\%83o-em-primeiro-lugar-uma-abordagem-honesta-sobre-a-questa $\%$ CC\%83odo-uso-das-drogas-por-adolescentes.pdf

8. Spósito MP, Carrano PCR. Juventudes e Políticas Públicas no Brasil. Revista Brasileira de Educação 2003; 4:16-39.

9. Soares CB. Consumo contemporâneo de drogas e juventude: a construção do objeto da perspectiva da saúde coletiva [tese]. São Paulo: Universidade de São Paulo; 2007.

10. Presidência da República. Secretaria Geral. Mapa do Encarceramento: os jovens do Brasil. Brasília: Presidência da República, 2015 Set. [acessado 2020 jan 23]. [cerca de 112 p.]. Disponível em: http://www.pnud. org.br/arquivos/encarceramento_WEB.pdf

11. Brasil. Ministério da Justiça e Segurança Pública. Levantamento Nacional de Informações Penitenciárias - Junho de 2017. [Acessado 2021 fev 26]. Disponível em: http://antigo.depen.gov.br/DEPEN/depen/sisdepen/infopen/relatorios-sinteticos/infopen-jun2017-rev-12072019-0721.pdf.

12. Flauzina ALP. Corpo negro caído no chão: o sistema penal e o projeto genocida do Estado brasileiro. Rio de Janeiro: Contraponto; 2008.
13. Carvalho FFB. A saúde vai à escola: a promoção da saúde em práticas pedagógicas. Physis [periódico de Internet]. $2015 \mathrm{dez}$ [acessado $2020 \mathrm{fev}$ 10]; 25(4):[cerca de 20 p.]. Disponível em: http:// www.scielo.br/scielo.php?script=sci_arttext\&pi$\mathrm{d}=$ S0103- $7^{33} 12015000401207 \& \operatorname{lng}=$ en

14. Schenker M, Minayo MCS. Fatores de risco e de proteção para o uso de drogas na adolescência. Cien Saude Coletiva [periódico de Internet]. 2005 set; [acessado 2020 fev 12]; 10(3):[cerca de 10 p.]. Disponível em: http://www.scielo.br/scielo.php?script=sci_arttex$\mathrm{t} \& \mathrm{pid}=\mathrm{S} 1413-81232005000300027 \& \operatorname{lng}=\mathrm{en}$.

15. Calazans G, Kiss L, Cappellini S, Sequeira D, Vieira R M, França J I. Plantões jovens: acolhimento e cuidado por meio da educação entre pares para adolescentes e jovens nos Centros de Testagem e Aconselhamento - CTA. Saúde Soc [periódico de Internet]. 2006 abr [acessado $2020 \mathrm{fev} 13$ ]; 15(1):[cerca de 14 p.].Disponível em: http://www.scielo.br/scielo.php?script=sci_ arttext\&pid=S0104-12902006000100004\&lng=en.

16. Figueiredo TAM, Machado VLT, Abreu MMS. A saúde na escola: um breve resgate histórico. Cien Saude Coletiva [periódico de Internet]. 2010 mar; [acessado $2021 \mathrm{fev} 25$ ]; 15(2):[cerca de 5p.]. Disponível em: https://www.scielo.br/scielo.php?script=sci_arttext\&pi$\mathrm{d}=$ S1413-81232010000200015

17. Saviani D. Pedagogia histórico-crítica: primeiras aproximações. Campinas: Autores Associados; 2003.

18. Ribeiro TM. Do você não quer ao você não pode: $a$ emergência da prevenção às drogas na educação. Curitiba: Appris; 2013.

19. Dalbosco C, Pereira A D. Introdução. In: Prevenção ao uso de drogas: a escola na rede de cuidados (Ano XXIII, Boletim 23). Rio de Janeiro: Salto para o futuro; 2013.

20. Silva M. Caraterização de projetos de educação pelos pares na área do consumo de substâncias psicoativas. Desenvolvimento e Sociedade [periódico de Internet]. 2019 set [acessado 2020 fev 3]; 6(1):[cerca de 8 p.]. Disponível em: http://www.revistas.uevora. $\mathrm{pt} /$ index.php/desenvolvimento_sociedade/article/ view/319/544

21. Bagnall A, South J, Hulme C, Woodall J, Vinall-Collier K, Raine G, Kinsella K, Dixey R, Harris L, Wright N MJ. A systematic review of the effectiveness and cos$\mathrm{t}$-effectiveness of peer education and peer support in prisons. BMC Public Health [serial on the Internet]. 2015 Set [cited 2020 Mar 27]. [cerca de 290p.]. Available from: https://bmcpublichealth.biomedcentral. com/articles/10.1186/s12889-015-1584-x

22. Ghasemi V, Simbar M. Fakari FR, Naz MSG, Kiani Z The Effect of Peer Education on Health Promotion of Iranian Adolescents: A Systematic Review. Intern J Pediatrics [serial on the Internet]. 2019 Mar [cited 2020 Mar 27]; 7(3):[cerca de 28 p.]. Available from: http:// ijp.mums.ac.ir/article_11814.html

23. Ayres JRCM, Freitas AC, Santos MAS, Saletti FHC, França JI. Adolescência e Aids: avaliação de uma experiência de educação preventiva entre pares. Interface (Botucatu) [periódico de Internet]. $2003 \mathrm{fev}$ [acessado 2020 abr 20]; 7(12):[cerca de 5 p.].Disponível em: $<$ http://www.scielo.br/scielo.php?script=sci_arttext\&pid=S141432832003000100009\&lng=en\&nrm=iso $>$. 
24. Surjus LTLS, Pupo J, Guerrero AVP, Scafuto JCB, organizadores. Planejando e realizando um curso sobre drogas e direitos humanos - Drogas e Direitos Humanos: Protagonismo, Educação entre pares e Redução de Danos. 2019 Abr [acessado 2020 fev 5]; 1(1):[cerca de 119 p.]. Disponível em: https://edelei.org/wp-content/uploads/2019/04/E-book-Drogas_Direitos_Humanos_final-1.pdf

25. Brasília: Ministério da Justiça; Fundação Oswaldo Cruz (Fiocruz). Termo de Execução Descentralizada (TED). Dispõe sobre a parceria entre Secretaria Nacional de Políticas Sobre Drogas. Projeto Prevenção ao Uso de Álcool e Outras Drogas no Território Educacional 2018-2020. Brasília: Ministério da Justiça; Fundação Oswaldo Cruz; 2018.

26. Brasil. Portaria Interministerial no 17 , de 24 de abril de 2007. Institui o Programa Mais Educação. Brasília: Ministério da Educação; 2007. [acessado 2020 jan 28]. Disponível em: http://portal.mec.gov.br/arquivos/pdf /mais_educacao.pdf

27. Freire P. Pedagogia do oprimido. Rio de Janeiro: Paz e Terra; 1987.

28. Hooks B. Ensinando a transgredir - a educação como prática de liberdade. São Paulo: WMF Martins Fontes; 2013.

29. Oliveira CSFA. Educação sexual de jovens a viver em meio institucional: desenvolvimento de um Programa de Educação pelos Pares no âmbito do Projeto Nacional de Educação pelos Pares da Fundação Portuguesa "A Comunidade Contra a SIDA" [dissertação]. Porto: Faculdade de Psicologia e de Ciências da Educação da Universidade do Porto; 2015

30. Brito I. Promoção da saúde nos jovens utilizando a educação pelos pares - Intervenção com estudantes de enfermagem e jovens enfermeiros. Enfermagem e o cidadão. Jornal da secção Regional do Centro da Ordem dos Enfermeiros 2009 Set: 7(19);6-9.

31. World Health Organization (WHO). The World Health Report 2002. Geneva: WHO; 2002. [acessado 2020 mar 30]. Disponível em: https://www.who.int/whr/2002/ en/

32. Buss PM; Pellegrini AF. A saúde e seus determinantes sociais. Rev Saude Coletiva [periódico de Internet]. $2007 \mathrm{fev}$ [acessado $2020 \mathrm{fev} \mathrm{10];} \mathrm{17(1):[cerca} \mathrm{de16}$ p.]. Disponível em: http://www.scielo.br/pdf/physis/ v17n1/v17n1a06.pdf

33. Bourdieu, P. A juventude é apenas uma palavra. In: Questões de sociologia. Rio de Janeiro: Marco Zero; 1983.

34. Racionais Mc's. Homem na Estrada [áudio]. São Paulo: Zimbabwe; 1993.
35. World Healthy Organization (WHO). Preventing suicide: a global imperative 2018 [Internet]. [acessado 2020 Apr 12]. Disponível em: https://www.who. int/mental_health/suicide-prevention/world_report_2014/en/

36. Birman J. Tatuando o desamparo: a juventude na atualidade. Adolescentes. Physis 2005 abr [acessado 2020 jan 17]; 15(1):[cerca de 5 p.] Disponível em: https:// www.ufrgs.br/psicoeduc/chasqueweb/edu01011/birman-tatuando-o-desamparo.pdf

37. Porto MSG. A violência entre a inclusão e a exclusão social. Tempo Soc [periódico de Internet].2000 mai [acessado 2020 jan 14]; 12(1):[cerca de 13 p.]. Disponível em: http://www.scielo.br/scielo.php?script= sci_arttext\&pid=S010320702000000100010\&lng = en\&nrm=iso $>$. http://dx.doi.org/10.1590/S0103-2070 2000000100010.

38. Raul Seixas. Prelúdio. Álbum Gitá; 1974.

39. Brasil. Ministério da Saúde (MS). Guia Adolescentes e jovens para a educação entre pares. Brasília: MS; 2010.

40. Köptcke LS, Padrão MRA, Rocha FG, Caixeta IA, Dalbosco C. Reflexões sobre o uso de material para educação entre pares no Programa Saúde na Escola. Com Cien Saude [periódico de Internet]. 2018 Mai [acessado 20/03/2020]; 28(2): [cerca de 21p.] Disponível em: $<$ http://www.escs.edu.br/revistaccs/index.php/comunicacaoemcienciasdasaude/article/view/219

41. Shiner M. Defining peer education. J Adolescence [serial on the Internet]. 1999 Ago [cited 2020 Apr 7]; 22(4):[about 11 p.]. Available from: https:// www.sciencedirect.com/science/article/abs/pii/ S0140197199902488

42. Silva Sobrinho AL. "Jovens de Projetos" nas ONGs: olhares e vivências entre o engajamento político e o trabalho no "social" [dissertação de mestrado]. Rio de Janeiro: Universidade Federal Fluminense; 2012.

Artigo apresentado em 29/04/2020

Aprovado em 31/03/2021

Versão final apresentada em 02/04/2021

Editores-chefes: Romeu Gomes, Antônio Augusto Moura da Silva 